\title{
OPTIMAL FINANCIAL AND ORDERING DECISIONS OF A FIRM WITH INSURANCE CONTRACT
}

\author{
Wenli WANG ${ }^{\mathrm{a}}$, Jianwen $\mathrm{LUO}^{\mathrm{b}}$ \\ aSchool of Economics and Management, Taiyuan University of Science and Technology, \\ 030024 Taiyuan, P.R. China \\ ${ }^{\mathrm{b} S}$ School of Management, Shanghai Jiao Tong University, \\ 200052 Shanghai, P.R. China
}

Received 06 March 2012; accepted 08 December 2012

\begin{abstract}
This paper examines the impact of a bank's risk limit on the financial and ordering decisions of a capital-constrained firm with insurance contract. All our major results can be computed via explicit expressions. It is shown that the bank will control its risk to be below the risk limit through setting a loan limit and the firm can make the loan limit increase by buying a deductible insurance policy. It is also shown that the repayment demand level needed to avoid bankruptcy will not be affected by the insurance policy. We derive the firm's optimal ordering quantity and insurance coverage level under a downside risk measurement and a variance risk measurement separately. It is shown that the firm should pay more attention to whether to buy insurance or not under the downside risk measurement and how much insurance coverage to buy under the variance risk measurement. Under the downside risk measurement, once the firm decides to buy insurance, the optimal coverage level is independent of the bank's risk limit. We also show that the insurance contract has a more obvious effect on the profit increases when the selling price is high or the bank's risk limit is low.
\end{abstract}

Keywords: capital constraint, deductible insurance, firm financing, newsvendor, risk.

JEL Classification: C61, G22, G31.

\section{Introduction}

Most start-up firms in retail industry have little fixed assets as collateral when they apply for loans. Banks often set a loan limit to mitigate default risk. In order to raise the loan limit set by banks, firms are often required to provide several channels to transfer banks' risk. Credit insurance financing solution provides firms the necessary financing to pay their suppliers using the

Corresponding author Wenli Wang

E-mail: wangwenli276@aliyun.com 
credit insurance policy as collateral to transfer banks' risk. The credit insurance companies, the banks and the firms only need to sign an agreement for transferring credit risk to the insurance companies. For example, Export Credit Insurance Financing, granted by China Guangfa Bank to an exporter, refers to a short term loan in a certain proportion to the goods value, after the exporter has bought the export credit insurance from China Export Credit Insurance Company, transferred the indemnity right to the bank, and shipped the goods. China Export Credit Insurance Company undertakes the credit risk of the importer; as long as the exporter fulfills the trade contract normally, the exporter can get the payment reception assurance (for more details of Export Credit Insurance Financing, go to: http://www.cgbchina.com.cn/Info/13134486).

Most of the traditional literature treat finance and operations as separate issues. However, most firms often need to make financial and operational decisions simultaneously. The interaction of financial and operational decisions of firms has been recognized by several researchers. Stiglitz (1972), Myers $(1974,1977)$ showed how a firm's investment decision affects its financial structure. Dotan and Ravid (1987) analysed the interaction between the optimal level of investment and debt financing. Anderson and Prezas (1998) studied the interaction of investment and financing decisions under moral hazard.

There is a growing body of literature in the operations management community focusing on the interface between operations management and finance. Buzacott and Zhang (2004) were among the first to incorporate asset-based financing into production decisions. Several researchers have studied the operational decisions of firms under capital constraints, such as Babich and Sobel (2004); Hu and Sobel (2005); Xu and Birge (2006); Hu and Sobel (2007); Li et al. (2013). Another stream of research has considered supply chain coordination under capital constraints. Representative works includes Guillen et al. (2007), Tsai (2008), Lai et al. (2009), Lee and Rhee (2010), Raghavan and Mishra (2011).

As we mentioned earlier, most start-up and fast-growing firms, especially in retail industry, have little fixed assets as collateral for loans. Thus, lenders of these firms may face significant risks under market uncertainties. For instance, in the Export Credit Insurance Financing, market uncertainties may be the credit risks of the importers and the political risks of the country or region where the importers live. The borrowers may be unable to repay the loan in full if their operations performances turn out to be poor. Although the existing researches have studied different methods to transfer credit risk, the interaction of operations and credit risk is not considered. Some literature have examined the relationship between credit risk and insurance. It is well known that default risk can be reduced by a credit insurance policy. Caillaud et al. (2000) rationalized the use of insurance covenants in financial contracts and showed how external financing generates a demand for insurance by risk-neutral company. Dermine and Lajeri (2001) studied bank lending explicitly and calculated loan-risk sensitive insurance premium. Lai and Soumar (2010) found that the presence of credit insurance yields high investment relative to the level of investment without credit insurance. Brian (2013) discussed the importance of credit insurance to facilitate smooth operation of a business. Our study differs from these papers in that we consider the impact of the risk limit of a bank on the insurance and operational decisions of a firm. 
In this paper, the financial and ordering decisions of a capital-constrained firm are analyzed using a newsvendor model. The firm sells a product in a single selling season. Customer demand is uncertain. Due to the capital constraint, the firm needs to borrow money from a bank and must decide on the amount of the loan before observing the random demand. After the demand is realized, the firm repays its debt by selling revenue. If the selling revenue is less than the promised repayment, the firm will be forced into bankruptcy and the bank will suffer losses. To mitigate such losses, the bank may set a loan limit to reduce risk, while the firm can buy a deductible insurance policy to encourage the bank raising its loan limit. We analyse the optimal ordering quantity and insurance coverage level of the firm, and the impact of the bank's risk limit on the firm's optimal decisions under a downside risk measurement and a variance risk measurement separately.

\section{The model}

Many classical operational problems under capital constraints have been studied using the newsvendor model. We refer readers to Kouvelis and Zhao (2011) for papers on this topic. We first describe the model setting of the classical newsvendor model and then we formulate our model. In the classical newsvendor model, a firm is assumed to sell a product in a single selling season at price of $p$. At the beginning of the selling season, the firm orders the items from its supplier at a unit wholesale price of $w<p$. The salvage value of each leftover item is assumed to be zero. Customer demand, denoted by $\xi$, is uncertain. Let $F(\cdot)$ be the cumulative distribution function and $f(\cdot)$ be the probability density function of $\xi$. Assume that $F(\cdot)$ is a continuous and strictly increasing function and $f(\cdot)$ is a nonnegative function in $[0, \infty)$. Suppose the firm orders $q$ units of the item at the beginning of the selling season, the risk-neutral newsvendor problem can be formulated as follows:

$$
\max _{q} E \pi(q)=\int_{0}^{q} p x f(x) d x+\int_{q}^{\infty} p q f(x) d x-w q .
$$

The optimal solution $q^{N}$ for problem (1) is called the firm's classical ordering quantity. It is straightforward to verify that the expected profit function is a concave function of $q$. Using the first-order optimality conditions, we obtain the firm's classical ordering quantity $q^{N}$ as follows:

$$
q^{N}=F^{-1}\left(1-\frac{w}{p}\right),
$$

where $F^{-1}(\cdot)$ is the inverse function of $F(\cdot)$.

In our model, we assume the firm's initial capital is zero. The firm does not offer its customers a delay in payment, i.e. the firm can immediately receive the payment as soon as it sells the items. The supplier also does not offer the firm a delay in payment, i.e. the firm has to borrow money from the bank for its ordering at the beginning of the season. At this time, both accounts payable period and accounts receivable period are equal to zero, so the cash-to-cash cycle time is equal to inventory period (recall that the cash-to-cash cycle time 
is calculated as accounts receivable period + inventory period - accounts payable period, which is discussed in Huang et al. (2005)). We assume away the inventory holding cost and opportunity cost to focus on the inventory risk, which is a common assumption in the single period capital-constrained newsvendor model. We refer readers to Buzacott and Zhang (2004), Lai et al. (2009), Kouvelis and Zhao (2011). Therefore, the cash-to-cash cycle time does not influence the firm's expected profit in our model. Of course, we can also think that the supplier offers the firm a delay in payment only for a short time and the firm has to pay the supplier before it gets sales revenue. Suppose the firm borrows $D$ from a bank with a promised repayment of $D(1+r(D))$, where $r(D)$ is the interest rate function depending on $D$ for this risky lending. We assume that the firm has no other investment opportunity. After the demand is realized, the firm sells the items it ordered. If the customer demand turns out to be high and the firm's selling revenue exceeds the promised repayment, the bank receives the repayment in the amount of $D(1+r(D))$. On the other hand, if the customer demand is lower and the firm's selling revenue is insufficient to repay its loan and interest, the bank forces the firm into bankruptcy to acquire the residual value of the firm. We assume the bank has full control of the firm's account, so that all cash receipts from customers will repay the bank's loan first. Additionally, we assume that the credit market is perfectly competitive and the risk-free interest rate is zero. Therefore, the bank will set the interest rate function such that the expected return equals to D. According to Buzacott and Zhang (2004), if the borrowing rate is greater than the risk-free rate, it is optimal for the firm to use up all the borrowing money for its ordering. In other words, $D=w q$, where $q$ is the firm's ordering quantity.

As we mentioned earlier, the bank will incur losses if the firm (i.e. the borrower) defaults. The bank often sets a risk limit to avoid a greater loss. As we show later, a risk limit is equal to a loan limit. In practice, the firm can choose to buy a deductible insurance policy to reduce the bank's risk. In return, the bank will increase its loan limit. The time schedule of the events is as follows: the bank sets a risk limit as risk control condition; the firm decides the ordering quantity and the insurance coverage level; if the firm's decisions satisfy the bank's risk control condition, the bank lends the money to the firm; the firm purchases the items from its suppliers; season demand occurs; the firm repays the loan to the bank; if the firm cannot repay the loan in full, it is forced into bankruptcy and the insurance company will guarantee that the bank could get a minimum revenue based on the insurance coverage level. The timeline of the events is shown in Figure 1.

In our model, information concerning the distribution of demand is assumed to be public, i.e. available to the bank and the insurance company. This may be true in the following situations. For the bank, it can cooperate with logistics companies, such as DHL, UPS, who can share the true information about the firm and the market with the bank before the bank grants the firm a loan, so information concerning the distribution can be thought as public knowledge between the bank and the firm (see Li et al. 2009). For the insurance company, there are two situations in which public information assumption is reasonable. First, the insurance company can easily forecast the information about the firm and the market in the traditional industries. For example, China Pacific Insurance Company mainly focuses its credit insurance business on food, textile and other traditional industries, but is rarely 


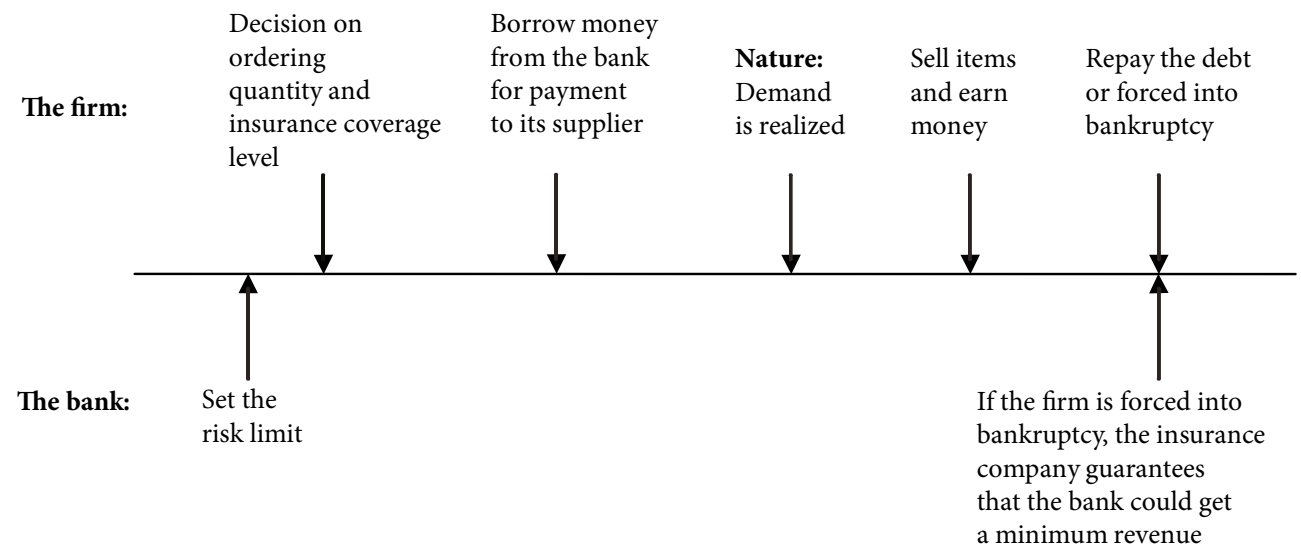

Fig. 1. The timeline of the events

involved in emerging industries. Second, policy-oriented insurance companies can easily obtain the customers' credit and the market information. For example, China Export Credit Insurance Company not only owns a huge database of information, but also cooperates with the Ministry of Commerce, the Customs and the Ministry of Foreign Affairs of China to obtain data resources (see Tang 2007).

We assume there is a perfectly competitive insurance market in which the insurer provides insurance at a fair price. We use $b$ to denote the insurance coverage level the firm purchases. Therefore, if the realized demand $\xi$ is less than the ordering quantity $q$ and the realized selling revenue $p \xi$ is less than the coverage level $b$, the insurer pays indemnity $b-p \xi$ to the bank, otherwise the insurer pays nothing. Since the insurance premium, denoted by $m(b)$, is assumed to be fair, using integration by parts, the premium can be written as:

$$
m(b)=\int_{0}^{\frac{b}{p}}(b-p x) f(x) d x=\int_{0}^{\frac{b}{p}} p F(x) d x
$$

And we have:

$$
\frac{d m(b)}{d b}=F\left(\frac{b}{p}\right) .
$$

We can see that the premium is increasing in the coverage level $b$, and the marginal premium is increasing in the coverage level and decreasing in the product's selling price. As we assumed earlier, the firm's initial capital is zero. Therefore, if the firm buys an insurance policy, it must increase its loan amount to $D=w q+m(b)$ to pay for the insurance premium. 


\section{The bank's risk control}

\subsection{The bank's expected cash flow}

Because $b$ is the coverage term of the insurance contract which the firm bought and put in pledge to the bank for a loan, it is reasonable that the bank knows $b$. Because the insurance premium is fair in the perfect competitive insurance market and the bank knows the demand information, the bank is certain to know $m(b)$. Of course, we can also assume the bank and the insurance company to be an integrated firm as discussed in Caillaud et al. (2000). The interest rate function, denoted by $r(q, b)$, now depends on both $q$ and $b$. After the market demand is realized and the firm repays the bank's loan, the bank's cash flow is as follows:

$$
Y(q, b, r(q, b))=\left\{\begin{array}{lr}
(w q+m(b))(1+r(q, b)) & \xi \geq z(q, b), \\
p \xi & \frac{b}{p} \leq \xi<z(q, b), \\
b & \xi<\frac{b}{p},
\end{array}\right.
$$

where $z(q, b)$ is derived by solving $p z(q, b)=(w q+m(b))(1+r(q, b))$. We call $z(q, b)$ the repayment demand level function.

Using integration by parts to simplify the expression, the expected value of the bank's future cash flow is as follows:

$$
\begin{aligned}
& E Y(q, b, r(q, b))=\int_{0}^{\frac{b}{p}} b f(x) d x+\int_{\frac{b}{p}}^{z(q, b)} p x f(x) d x+\int_{z(q, b)}^{\infty}(w q+m(b))(1+r(q, b)) f(x) d x= \\
& (w q+m(b))(1+r(q, b))-\int_{\frac{b}{p}}^{z(q, b)} p F(x) d x .
\end{aligned}
$$

According to Dotan and Ravid (1987), Lai et al. (2009), in a competitive financial market, the bank will approve a loan if and only if the bank expects that it can break even. That is, the bank sets $r^{*}(q, b)$ as the interest rate function to guarantee that the expected return equals the risk-free return, where $r^{*}(q, b)$ must satisfy the following equation:

$$
E Y\left(q, b, r^{*}(q, b)\right)=(w q+m(b))\left(1+r^{*}(q, b)\right)-\int_{\frac{b}{p}}^{z^{*}(q, b)} p F(x) d x=w q+m(b),
$$

where $z^{*}(q, b)$ satisfies $p z^{*}(q, b)=(w q+m(b))\left(1+r^{*}(q, b)\right)$. We call $z^{*}(q, b)$ the repayment demand level function of a competitive financial market.

Lemma 1. In a competitive financial market, the interest rate is decreasing in $b$; the repayment demand level function $z^{*}(q, b)$ is increasing in $q$ and is independent of $b$. That is, $z^{*}(q, b)=z^{*}(q)$ for any $b$. 
Proof: From Eq. (7), let

$$
\begin{aligned}
& M\left(q, r^{*}(q, b), b\right) \equiv \\
& (w q+m(b))\left(1+r^{*}(q, b)\right)-\int_{\frac{b}{p}}^{\frac{(w q+m(b))\left(1+r^{*}(q, b)\right)}{p}} p F(x) d x-w q-m(b) .
\end{aligned}
$$

Based on Implicit Function Theorem, we have:

$$
\begin{gathered}
\frac{\partial r^{*}(q, b)}{\partial b}=-\frac{\partial M\left(q, r^{*}(q, b), b\right) / \partial b}{\partial M\left(q, r^{*}(q, b), b\right) / \partial r^{*}(q, b)}=-\frac{\left(1+r^{*}(q, b)\right) F\left(\frac{b}{p}\right)}{w q+m(b)}<0 ; \\
\frac{\partial r^{*}(q, b)}{\partial q}=-\frac{\partial M\left(q, r^{*}(q, b), b\right) / \partial q}{\partial M\left(q, r^{*}(q, b), b\right) / \partial r^{*}(q, b)}=-\frac{w\left(1+r^{*}(q, b)\right)\left[1-F\left(z^{*}(q, b)\right)\right]-w}{(w q+m(b))\left[1-F\left(z^{*}(q, b)\right)\right]} .
\end{gathered}
$$

According to the definition, we know $z^{*}(q, b)=(w q+m(b))\left(1+r^{*}(q, b)\right) / p$ and we have:

$$
\begin{gathered}
\frac{\partial z^{*}(q, b)}{\partial q}=\frac{w\left(1+r^{*}(q, b)\right)}{p}+\frac{(w q+m(b))}{p} \frac{\partial r^{*}(q, b)}{\partial q}=\frac{w}{p\left[1-F\left(z^{*}(q, b)\right)\right]}>0 ; \\
\frac{\partial z^{*}(q, b)}{\partial b}=\frac{1+r^{*}(q, b)}{p} \frac{d m(b)}{d b}+\frac{w q+m(b)}{p} \frac{\partial r^{*}(q, b)}{\partial b}=0
\end{gathered}
$$

which implies the results.

From Lemma 1, we know that for a certain ordering quantity, if the firm buys higher insurance coverage level, it will get lower interest rate from the bank. However, for a certain coverage level, procuring more items does not mean that the firm needs to pay more interests for the loan or can get lower interest rate. For a certain coverage level, if the firm orders more items, it needs higher customer demand level to avoid bankruptcy. However, it is surprising that for a certain ordering quantity, insurance coverage level does not affect repayment demand level needed to avoid bankruptcy. On the one hand, the insurance premium increases and the loan amount increases accordingly with the coverage level. On the other hand, the bank's interest rate decreases with the coverage level. These two effects balance out each other which result in an unchanged repayment demand level for any given coverage level. That is to say, it is not necessary to worry about the increasing of bankruptcy probability when the firm makes a decision on buying insurance. Since the repayment demand level function $z^{*}(q, b)$ is independent of $b$, we can replace $z^{*}(q, b)$ with $z^{*}(q)$ in the following context.

With insurance financing, the firm borrows $w q+m(b)$ from the bank and should repay $(w q+m(b))\left(1+r^{*}(q, b)\right)$ at the end of the season. What we want to know is whether the firm will buy an insurance coverage level between $w q+m(b)$ and $(w q+m(b))\left(1+r^{*}(q, b)\right)$. Lemma 2 gives us the answer. 
Lemma 2. In a competitive financial market, for any given $q, b \leq w q+m(b)$ always holds. The result indicates that the firm will not buy a deductible insurance coverage level in excess of the loan.

Proof: Given $q$, we define $b^{\max }$ as the maximum of the insurance coverage. Obviously, $b^{\text {max }}$ satisfies $b^{\text {max }}=\left(w q+m\left(b^{\text {max }}\right)\right)\left(1+r^{*}\left(q, b^{\text {max }}\right)\right)$. According to Lemma 1 , we have $b^{\text {max }}=p z^{*}\left(q, b^{\text {max }}\right)=p z^{*}(q)$. Hence, for each $b$ that satisfies $b<(w q+m(b))\left(1+r^{*}(q, b)\right)=$ $p z^{*}(q)$, we have $b<b^{\text {max }}$. According to Eq. (7), wehave $r^{*}\left(q, b^{\text {max }}\right)=0$, i.e. $b^{\text {max }}=w q+m\left(b^{\text {max }}\right)$. Define $T(b) \equiv b-w q-m(b)$ and we have:

$$
\frac{d T(b)}{d b}=1-F\left(\frac{b}{p}\right)>0,
$$

which implies that $T(b)$ is increasing in $b$. Hence, for $b<b^{\max }, T(b)<T\left(b^{\max }\right)=0$ and $b<w q-m(b)$. It implies $b \leq w q-m(b)$ holds at all time.

\subsection{The bank's loan limit under a downside risk measurement}

Because of the uncertainty of the market demand, the bank's future cash flow may be more or less than the lending amount, i.e. the bank granting the firm a loan can be risky. Li et al. (2011) analysed various risk measurement approaches, such as mean-variance, value-atrisk (VaR), conditional value-at-risk ( $\mathrm{CVaR})$, downside risk. First, we study the impact of an insurance policy on the loan limit under a downside risk measurement. Loans become non-performing when borrowers stop making payments and the loans enter default. Banks often use the ratio of non-performing loans (NPL) to total loans as a measure of the quality of their loans. A smaller NPL ratio indicates smaller losses for banks. In our mode, the bank's NPL ratio is $\left[w q+m(b)-Y\left(q, b, r^{*}(q, b)\right)\right] /(w q+m(b))$. Let $\alpha(0<\alpha<1)$ be the target NPL ratio, then the downside risk of the bank is defined to be the probability that its performing loan ratio is less than $1-\alpha$, i.e. $\operatorname{Pro}\left\{Y\left(q, b, r^{*}(q, b)\right)<(1-\alpha)(w q+m(b))\right\}$. Let $\beta(0<\beta<1)$ be the bank's risk limit, which refers to the bank's risk tolerance degree. Then the bank's risk control should let the downside risk satisfy $\operatorname{Pro}\left\{Y\left(q, b, r^{*}(q, b)\right)<(1-\alpha)(w q+m(b))\right\} \leq \beta$, i.e. the probability that its performing loan ratio is less than $1-\alpha$ should be at most $\beta$. Unlike the newsvendor model with a VaR constraint which only consider the newsvendor's risk preference in Jammernegg and Kischka (2012), in our model the objective is to maximize the firm's expected profit and the bank's risk control is used as a constraint, i.e. the firm is risk neutral and the bank is risk averse. It is easy to see that the firm's optimal insurance decision satisfies $b=0$ or $b \geq(1-\alpha)(w q+m(b))$. The relationship between the insurance coverage level and the loan limit under the downside risk control is described in Proposition 1.

Proposition 1. Under the downside risk measurement, (1) without insurance, the bank will set the loan limit as $\bar{D}=w \bar{q}$, where $\bar{q}=\bar{q}_{0} \equiv \frac{p}{(1-\alpha) w} F^{-1}(\beta)$ is the ordering limit; (2) with the insurance policy of coverage level $b$ the bank will set the loan limit as $\bar{D}=\frac{b}{1-\alpha}$, and the firm's ordering limit is $\bar{q}=\bar{q}_{d}(b) \equiv \frac{b}{(1-\alpha) w}-\frac{m(b)}{w}$, and $\bar{q}_{d}(b)$ is increasing in $b$. 
Proof: When $b=0$, the bank's downside risk is $\operatorname{Pro}\{p \xi<(1-\alpha) w q\}=F\left(\frac{(1-\alpha) w q}{p}\right)$. To let its downside risk be no more than the risk limit, the bank will set the loan limit as $\bar{D}=w \bar{q}_{0}$, where $\bar{q}_{0}=\frac{p}{(1-\alpha) w} F^{-1}(\beta)$ is the ordering limit. When $b \geq(1-\alpha)(w q+m(b))$, the bank's downside risk is $\operatorname{Pro}\{b<(1-\alpha)(w q+m(b))\}=0$ which is always less than the risk limit. Let $R(q)=b-(1-\alpha)(w q+m(b))$. Because $R^{\prime}(q)<0$, given $b$, there exists a critical value $\bar{q}_{d}(b)$ such that when $q>\bar{q}_{d}(b)$, we have $R(q)<0$ and $\operatorname{Pro}\{b<(1-\alpha)(w q+m(b))\}=1$; when $q \leq \bar{q}_{d}(b)$, we have $R(q) \geq 0$ and Pro $\{b<(1-\alpha)(w q+m(b))\}=0$. That is to say, the firm's ordering limit is $\bar{q}_{d}(b)$. Because

$$
\frac{d \bar{q}_{d}(b)}{d b}=\frac{1-(1-\alpha) F\left(\frac{b}{p}\right)}{(1-\alpha) w}>0
$$

$\bar{q}_{d}(b)$ is increasing in $b$.

From Proposition 1, under the downside risk measurement, the bank will set a loan limit to control its risk to be below the risk limit. Without insurance, the loan limit increases with the risk limit, so does the ordering limit. With the insurance policy of coverage level $b$, the loan limit equals to the inflated coverage level, where the inflation factor is $(1 / 1-\alpha)$. Interestingly, both the loan limit and the ordering limit are independent of the risk limit. There exists a critical value $\bar{b}$ satisfying $\bar{q}_{d}(\bar{b})=\frac{p}{(1-\alpha) w} F^{-1}(\beta)$ such that when the coverage level is no more than the critical value, the insurance policy does not work for raising the bank's loan limit; when the coverage level is higher than the critical value, the insurance policy can raise the bank's loan limit. That is to say, under the downside risk measurement, the firm should buy an insurance of high coverage level, or the firm should not buy insurance.

\subsection{The bank's loan limit under a variance risk measurement}

Since the bank earns zero profit in the perfect competitive financial market in our model, the bank's risk can be denoted by the variance of this risky lending. Next, we study the impact of an insurance policy on the loan limit under a variance risk measurement as follows:

$$
\begin{aligned}
& \operatorname{VarY}\left(q, b, r^{*}(q, b)\right)=E Y^{2}\left(q, b, r^{*}(q, b)\right)-\left[E Y\left(q, b, r^{*}(q, b)\right)\right]^{2}=\int_{0}^{\frac{b}{p}} b^{2} f(x) d x+ \\
& \int_{\frac{b}{p}}^{z^{*}(q)} p^{2} x^{2} f(x) d x+\int_{z^{\star}(q)}^{\infty}(w q+m(b))^{2}\left(1+r^{*}(q, b)\right)^{2} f(x) d x-(w q+m(b))^{2}= \\
& (w q+m(b))^{2}\left(1+r^{*}(q, b)\right)^{2}-\int_{\frac{b}{p}}^{z^{*}(q)} 2 p^{2} x F(x) d x-(w q+m(b))^{2} .
\end{aligned}
$$

Therefore, the bank's risk is affected by the firm's decisions of $q$ and $b$. Next, we study the impact of the change of the firm's ordering quantity and insurance coverage level on the bank's risk, and we have Lemma 3. 
Lemma 3. In a competitive financial market, the bank's risk is increasing in $q$ and decreasing in $b$.

Proof: Taking derivatives with respect to $q$ and $b$, we obtain:

$$
\begin{aligned}
& \frac{\partial \operatorname{Var} Y\left(q, b, r^{*}(q, b)\right)}{\partial q}= \\
& 2(w q+m(b)) w\left(1+r^{*}(q, b)\right)^{2}+(w q+m(b))^{2} 2\left(1+r^{*}(q, b)\right) \frac{\partial r^{*}(q, b)}{\partial q}- \\
& 2 p^{2} z^{*}(q) F\left(z^{*}(q)\right) \frac{d z^{*}(q)}{d q}-2(w q+m(b)) w=2 w r^{*}(q, b)(w q+m(b)) ; \\
& \frac{\partial \operatorname{Var} Y\left(q, b, r^{*}(q, b)\right)}{\partial b}= \\
& 2(w q+m(b)) \frac{d m(b)}{d b}\left(1+r^{*}(q, b)\right)^{2}+(w q+m(b))^{2} 2\left(1+r^{*}(q, b)\right) \frac{\partial r^{*}(q, b)}{\partial b}+2 b F\left(\frac{b}{p}\right)- \\
& 2(w q+m(b)) \frac{d m(b)}{d b}=-2(w q+m(b)-b) F\left(\frac{b}{p}\right) \cdot
\end{aligned}
$$

It is easy to see that $\frac{\partial \operatorname{Var} Y\left(q, b, r^{*}(q, b)\right)}{\partial q} \geq 0$ holds. According to Lemma 2, we have $\frac{\partial \operatorname{Var} Y\left(q, b, r^{*}(q, b)\right)}{\partial b} \leq 0$. For any $b$ that satisfies $b<w q+m(b)$, the two inequalities hold strictly. Hence, in a competitive financial market, the bank's risk is increasing in $q$ and decreasing in $b$.

Due to government regulation, we assume the bank must limit its risk within a fixed range. To achieve this goal, the bank has to set a loan limit since the risk is increasing in the firm's ordering quantity according to Lemma 3. In order to get a higher loan limit, the firm can purchase an insurance policy to reduce the bank's risk. We assume that the bank sets risk limit as $\overline{v a r}$. The relationship between the insurance coverage level and the loan limit under the variance risk control is described in Proposition 2.

Proposition 2. Under the variance risk measurement, with the insurance policy of coverage level $b$, the bank will set the loan limit as $\bar{D}=w \bar{q}+m(b)$, where $\bar{q}=\bar{q}_{v}(b)$ is the ordering limit function that satisfies $\operatorname{Var} Y\left(\bar{q}_{v}(b), b, r^{*}\left(\bar{q}_{v}(b), b\right)\right)=\overline{v a r}$, and $\bar{q}_{v}(b)$ is increasing in $b$.

Proof: According to Lemma 3, the risk taken by the bank is increasing in $q$, and given the bank's risk limit $\overline{v a r}, \bar{q}_{v}(b)$ solves $\operatorname{Var} Y\left(\bar{q}_{v}(b), b, r^{*}\left(\bar{q}_{v}(b), b\right)\right)=\overline{v a r}$.

Let $V\left(\bar{q}_{v}(b), b\right)=\operatorname{Var} Y\left(\bar{q}_{v}(b), b, r^{*}\left(\bar{q}_{v}(b), b\right)\right)-\overline{v a r}$. Based on Implicit Function Theorem, we have:

$$
\frac{d \bar{q}_{v}(b)}{d b}=-\frac{\partial V\left(\bar{q}_{v}(b), b\right) / \partial b}{\partial V\left(\bar{q}_{v}(b), b\right) / \partial \bar{q}_{v}(b)}=\frac{\left(w \bar{q}_{v}(b)+m(b)-b\right) F\left(\frac{b}{p}\right)}{w r^{*}\left(\bar{q}_{v}(b), b\right)\left(w \bar{q}_{v}(b)+m(b)\right)}>0
$$

Hence, the ordering limit is increasing in the insurance coverage level $b$. 
From Proposition 2, under the variance risk measurement, the bank will also control its risk through setting a loan limit. If the firm buys higher insurance coverage level, the loan limit is higher and the firm can obtain opportunities of earning more profit since it can borrow more money from the bank. However, the firm needs to pay a higher insurance premium. Conversely, if the firm buys lower insurance coverage, the loan limit is lower and the firm may lose some market chance since it can only borrow less money from the bank. Of course, the firm does not need to pay too much premium. For given $b$, both the loan limit and the ordering limit are increasing in the risk limit.

\section{The firm's optimal ordering and insurance decisions}

Since buying insurance increases the cost and also increases the ordering limit, the firm needs to decide the optimal ordering quantity and insurance coverage level to maximize its expected profit. In theory, the bank will let the firm know its risk control policy, i.e. the risk limit, so that the firm can make the optimal ordering and insurance decisions to satisfy the bank's risk control condition. In practice, the bank usually cooperates with the insurance company to design a financing plan for the firm. For example, in July 2012, China Export Credit Insurance Company and Bank of China jointly signed to Sunivo, a supply chain solutions provider, launched credit insurance, credit financing and other financial services specifically for small and medium-sized enterprises' import and export business (see Yi 2012). They have published a menu, from which the firm knows how much coverage should be bought for a certain loan. Another channel from which the firm knows the bank's risk limit is cross selling. For example, China Export Credit Insurance Company and China Construction Bank have cooperated with each other and performed cross selling. When the firm applies for a loan to the bank, the bank will introduce its risk control policy and prompt the firm to use the credit insurance financing method. Also, when the insurance company's client faces financial difficulties, the insurance company will recommend the cooperative bank and introduce its risk control policy to the client (see Pan 2008).

We observe that $p q \geq(w q+m(b))\left(1+r^{*}(q, b)\right)$ must hold to guarantee the firm's participation. It is easy to see that the inequality holds if $p$ is big enough or $w$ is small enough. In other words, the product market's profit rate has to be high enough to ensure the firm's participation. If the product profit margin is not high enough (i.e. $p q \geq(w q+m(b))\left(1+r^{*}(q, b)\right)$, does not hold), it is not profitable for the firm to carry and sell the product.

\subsection{The firm's expected profit}

The firm's future profit in a competitive financial market can be calculated as follows:

$$
\pi(q, b)=\left\{\begin{array}{lr}
p q-(w q+m(b))\left(1+r^{*}(q, b)\right), & \xi \geq q ; \\
p \xi-(w q+m(b))\left(1+r^{*}(q, b)\right), & z^{*}(q) \leq \xi<q ; \\
0, & \xi<z^{*}(q),
\end{array}\right.
$$


With the bank's breakeven condition, the firm's expected profit is:

$$
\begin{aligned}
& E \pi(q, b)=\int_{z^{*}(q)}^{q}\left[p x-(w q+m(b))\left(1+r^{*}(q, b)\right)\right] f(x) d x+ \\
& \int_{q}^{\infty}\left[p q-(w q+m(b))\left(1+r^{*}(q, b)\right)\right] f(x) d x-m(b)= \\
& \int_{0}^{q} p x f(x) d x+\int_{q}^{\infty} p q f(x) d x-(w q+m(b)) .
\end{aligned}
$$

We find that the firm's expected profit function with the insurance contract is equal to the classical expected profit function less the premium function.

With the bank's loan limit, the firm's optimization model can be formulated by:

$$
\begin{gathered}
\max _{q, b} E \pi(q, b)=\int_{0}^{q} p x f(x) d x+\int_{q}^{\infty} p q f(x) d x-(w q+m(b)) ; \\
\text { s.t. } q \leq \bar{q} .
\end{gathered}
$$

\subsection{The firm's decisions under the downside risk measurement}

From Eq. (21), we can see that the firm's expected profit function is concave with respect to $q$ and attains the maximum at $q=q^{N}$ for given $b$. If $\bar{q}_{0} \geq q^{N}$, the bank's risk control will not restrict the firm's optimal ordering decision. Since the firm's expected profit is decreasing in $b$ for given $q$, the firm will not buy insurance. If $\bar{q}_{0}<q^{N}$, without insurance, the firm cannot choose the classical ordering quantity. According to the analysis in Section 2.2, the firm's optimal insurance decision satisfies $b=0$ or $b \geq(1-\alpha)(w q+m(b))$. When $b=0$, the firm's optimal ordering quantity is $\bar{q}_{0}$. We define the firm's optimal expected profit as $\Pi^{\star}(0)$. When $b \geq(1-\alpha)(w q+m(b))$, i.e. $q \leq \bar{q}_{d}(b)$, since $\bar{q}_{d}(b)$ is increasing in $b$ and the firm's expected profit is decreasing in $b$, the firm's optimal insurance coverage level should let its ordering quantity be equal to $\bar{q}_{d}(b)$ and the firm's optimization model can be formulated as:

$$
\max _{b} E \pi(b)=\int_{0}^{\bar{q}_{d}(b)} p x f(x) d x+\int_{\bar{q}_{d}(b)}^{\infty} p \bar{q}_{d}(b) f(x) d x-\left(w \bar{q}_{d}(b)+m(b)\right)
$$

We solve the optimization problem above and define the firm's optimal insurance coverage level and optimal expected profit as $b^{S}$ and $\Pi^{*}\left(b^{S}\right)$. Comparing $\Pi^{*}(0)$ with $\Pi^{*}\left(b^{S}\right)$, we have the following proposition.

Proposition 3. Under the downside risk measurement, (1) if $\bar{q}_{0} \geq q^{N}$, i.e. $\beta \geq F\left(\frac{(1-\alpha) w q^{N}}{p}\right)$, the firm's optimal insurance coverage level is $b^{*}=0$ and optimal ordering quantity is $q^{*}=q^{N} ;(2)$ if $\bar{q}_{0}<q^{N}$, i.e. $\beta<F\left(\frac{(1-\alpha) w q^{N}}{p}\right)$, the firm's optimal insurance coverage level is $b^{*}=0$ for $\Pi^{*}(0) \geq \Pi^{*}\left(b^{S}\right)$ and $b^{*}=b^{S}$ for $\Pi^{*}(0)<\Pi^{*}\left(b^{S}\right)$ and optimal ordering quantity is $q^{*}=\bar{q}_{0}$ for $b^{*}=0$ and $q^{*}=\bar{q}_{d}\left(b^{S}\right)$ for $b^{*}=b^{S}$, where $b^{S}$ satisfies: 


$$
\frac{p}{w}\left[\frac{1}{1-\alpha}-F\left(\frac{b^{S}}{p}\right)\right]\left[1-F\left(\bar{q}_{d}\left(b^{S}\right)\right)\right]=\frac{1}{1-\alpha} .
$$

Proof: If $\bar{q}_{0}<q^{N}$, solving the optimization problem in Eq. (23), we have:

$$
\frac{d E \pi(b)}{d b}=\frac{p}{w}\left[\frac{1}{1-\alpha}-F\left(\frac{b}{p}\right)\right]\left[1-F\left(\bar{q}_{d}(b)\right)\right]-\frac{1}{1-\alpha} .
$$

Because $\frac{d E \pi(b)}{d b}$ is decreasing in $b, E \pi(b)$ is concave and attains the maximum at $b=b^{S}$, where $b^{S}$ is the unique solution which lets Eq. (25) be equal to zero. Also we should compare the firm's optimal expected profit when $b=b^{S}$ with that when $b=0$. The firm's optimal insurance coverage level is the one which lets its expected profit be higher.

From Proposition 3, when the bank's downside risk limit is no lower than a certain level, the bank's loan limit is higher than the loan amount needed for the classical ordering quantity and the firm will not buy insurance. That is because buying insurance will add the firm's cost, i.e. transfer part of the firm's profit to the insurance company who shares the market demand risk. When the bank's risk limit is lower than the certain level, the firm should buy an insurance policy or not depends on whether its expected profit increases arising from the increase of ordering quantity are larger than the insurance premium. Moreover, it is interesting that $b^{S}$ is independent of $\beta$, i.e. the optimal coverage level is independent of the bank's downside risk limit when the firm decides to buy an insurance policy. That is because the firm's optimal ordering quantity is equal to the ordering limit when buying insurance and the ordering limit is independent of $\beta$. The firm should lay more attention on whether to buy insurance instead of too much attention on the amount of coverage. Once the firm buys an insurance policy, the bank's NPL ratio will be controlled to be below the target level.

\subsection{The firm's decisions under the variance risk measurement}

Under the variance risk measurement, Eq. (22) becomes $q \leq \bar{q}_{v}(b)$. Solving the firm's optimization problem, we have the following proposition.

Proposition 4. Under the variance risk measurement, (1) if $\bar{q}_{v}(0) \geq q^{N}$, i.e. $\overline{\operatorname{var}} \geq \operatorname{Var} Y\left(q^{N}, 0, r^{*}\left(q^{N}, 0\right)\right)$, the firm's optimal insurance coverage level is $b^{*}=0$ and optimal ordering quantity is $q^{*}=q^{N}$; (2) if $\bar{q}_{v}(0)<q^{N}$, i.e. $\overline{\operatorname{var}}<\operatorname{Var} Y\left(q^{N}, 0, r^{*}\left(q^{N}, 0\right)\right)$, the firm's optimal insurance coverage level $b^{*}$ and optimal ordering quantity $q^{*}$ satisfy:

$$
\left\{\begin{array}{l}
q^{*}=F^{-1}\left[1-\frac{w\left(\left(w q^{*}+m\left(b^{*}\right)\right)\left(1+r^{*}\left(q^{*}, b^{*}\right)\right)-b^{*}\right)}{p\left(w q^{*}+m\left(b^{*}\right)-b^{*}\right)}\right] ; \\
\left(w q^{*}+m\left(b^{*}\right)\right)^{2}\left(1+r^{*}\left(q^{*}, b^{*}\right)\right)^{2}-\int_{\frac{b^{*}}{p}}^{\left.z^{*} q^{*}\right)} 2 p^{2} x F(x) d x-\left(w q^{*}+m\left(b^{*}\right)\right)^{2}=\overline{v a r} .
\end{array}\right.
$$


Proof: Given $b, E \pi(q, b)$ is concave with respect to $q$, increasing for $q \leq q^{N}$ and decreasing for $q \geq q^{N}$. Hence if $\bar{q}_{v}(b) \geq q^{N}$, then the optimal ordering quantity is $q^{*}=q^{N}$; else if $\bar{q}_{v}(b)<q^{N}$, then the optimal ordering quantity is $q^{*}=\bar{q}_{v}(b)$. Because $E \pi(q, b)$ is decreasing with respect to $b$. Hence if $\bar{q}_{v}(0) \geq q^{N}$, because $\operatorname{Var} Y\left(q, b, r^{*}(q, b)\right)$ is increasing in $q$, we have $\overline{v a r}=\operatorname{VarY}\left(\bar{q}_{v}(0), 0, r^{*}\left(\bar{q}_{v}(0), 0\right)\right) \geq \operatorname{VarY}\left(q^{N}, 0, r^{*}\left(q^{N}, 0\right)\right)$ and the firm's optimal ordering quantity is $q^{*}=q^{N}$ and optimal insurance coverage level is $b^{*}=0$. If $\bar{q}_{v}(0)<q^{N}$, i.e. $\overline{\operatorname{var}}<\operatorname{Var} Y\left(q^{N}, 0, r^{*}\left(q^{N}, 0\right)\right)$, define $b^{N}$ which satisfies $\bar{q}_{v}\left(b^{N}\right)=q^{N}$ and we have $b^{*} \leq b^{N}$ and $q^{*}=\bar{q}_{v}\left(b^{*}\right)$, i.e. Eq. (22) can be changed into:

$$
\operatorname{VarY}\left(q, b, r^{*}(q, b)\right)=\overline{\operatorname{var}} .
$$

Defining $\lambda$ as the multiplier of the optimization model, the Lagrangean function is:

$$
\begin{aligned}
& L(q, b, \lambda)= \\
& \int_{0}^{q} p x f(x) d x+\int_{q}^{\infty} p q f(x) d x-(w q+m(b))-\lambda\left[(w q+m(b))^{2}\left(1+r^{*}(q, b)\right)^{2}-\right. \\
& \left.\int_{\frac{b}{q}}^{z^{*}(q)} 2 p^{2} x F(x) d x-(w q+m(b))^{2}-\overline{v a r}\right] .
\end{aligned}
$$

Taking derivatives with respect to $q, b$ and $\lambda$, we obtain:

$$
\begin{gathered}
\frac{\partial L(q, b, \lambda)}{\partial q}=p[1-F(q)]-w-2 \lambda w r^{*}(q, b)(w q+m(b)) \\
\frac{\partial L(q, b, \lambda)}{\partial b}=-F\left(\frac{b}{p}\right)+2 \lambda(w q+m(b)-b) F\left(\frac{b}{p}\right) \\
\frac{\partial L(q, b, \lambda)}{\partial \lambda}=(w q+m(b))^{2}\left(1+r^{*}(q, b)\right)^{2}-\int_{\frac{b}{p}}^{z^{*}(q)} 2 p^{2} x F(x) d x-(w q+m(b))^{2}-\overline{v a r} .
\end{gathered}
$$

To find $q^{*}, b^{*}$ and $\lambda^{*}$, set Eqs (29), (30), (31) equal to zero and we have:

$$
\begin{gathered}
\lambda^{*}=\frac{1}{2\left(w q^{*}+m\left(b^{*}\right)-b^{*}\right)} ; \\
q^{*}=F^{-1}\left[1-\frac{w\left(\left(w q^{*}+m\left(b^{*}\right)\right)\left(1+r^{*}\left(q^{*}, b^{*}\right)\right)-b^{*}\right)}{p\left(w q^{*}+m\left(b^{*}\right)-b^{*}\right)}\right] ; \\
\left(w q^{*}+m\left(b^{*}\right)\right)^{2}\left(1+r^{*}\left(q^{*}, b^{*}\right)\right)^{2}-\int_{\frac{b^{*}}{p}}^{z^{*}\left(q^{*}\right)} 2 p^{2} x F(x) d x-\left(w q^{*}+m\left(b^{*}\right)\right)^{2}=\overline{v a r} .
\end{gathered}
$$


We compute the second-order partials:

$$
\begin{gathered}
\frac{\partial^{2} L\left(q^{*}, b^{*}, \lambda^{*}\right)}{\partial q^{2}}=-p f\left(q^{*}\right)-2 \lambda^{*} w^{2}\left[\frac{F\left(z^{*}\left(q^{*}\right)\right)}{1-F\left(z^{*}\left(q^{*}\right)\right)}\right]= \\
-p f\left(q^{*}\right)-\frac{w^{2}}{w q^{*}+m\left(b^{*}\right)-b^{*}}\left[\frac{F\left(z^{*}\left(q^{*}\right)\right)}{1-F\left(z^{*}\left(q^{*}\right)\right)}\right]<0 ; \\
\frac{\partial^{2} L\left(q^{*}, b^{*}, \lambda^{*}\right)}{\partial b^{2}}=-\frac{1}{p} f\left(\frac{b^{*}}{p}\right)-2 \lambda^{*}\left[1-F\left(\frac{b^{*}}{p}\right)\right] F\left(\frac{b^{*}}{p}\right)-\frac{2\left(w q^{*}+m\left(b^{*}\right)-b^{*}\right)}{p} f\left(\frac{b^{*}}{p}\right)= \\
\left.-\frac{\left.1-F\left(\frac{b^{*}}{p}\right)\right] F\left(\frac{b^{*}}{p}\right)}{w q^{*}+m\left(b^{*}\right)-b^{*}}<0 ; \quad \frac{w F\left(\frac{b^{*}}{p}\right)}{\partial q}\right) \\
\frac{\partial^{2} L\left(q^{*}, b^{*}, \lambda^{*}\right)}{\partial q \partial b}=\frac{\partial^{2} L\left(q^{*}, b^{*}, \lambda^{*}\right)}{\partial b \partial q}=2 \lambda^{*} w F\left(\frac{b^{*}}{p}\right)=\frac{w q^{*}+m\left(b^{*}\right)-b^{*}}{p}=0
\end{gathered}
$$

and form the Hessian:

$$
\begin{aligned}
& |H|=\left|\begin{array}{ll}
\frac{\partial^{2} L\left(q^{*}, b^{*}, \lambda^{*}\right)}{\partial q^{2}} & \frac{\partial^{2} L\left(q^{*}, b^{*}, \lambda^{*}\right)}{\partial q \partial b} \\
\frac{\partial^{2} L\left(q^{*}, b^{*}, \lambda^{*}\right)}{\partial b \partial q} & \frac{\partial^{2} L\left(q^{*}, b^{*}, \lambda^{*}\right)}{\partial b^{2}}
\end{array}\right|= \\
& \frac{p f\left(q^{*}\right) F\left(\frac{b^{*}}{p}\right)}{w q^{*}+m\left(b^{*}\right)-b^{*}}\left[1-F\left(\frac{b^{*}}{p}\right)\right]+\frac{w^{2} F\left(\frac{b^{*}}{p}\right)}{\left(w q^{*}+m\left(b^{*}\right)-b^{*}\right)^{2}}\left[\frac{F\left(z^{*}\left(q^{*}\right)\right)-F\left(\frac{b^{*}}{p}\right)}{1-F\left(z^{*}\left(q^{*}\right)\right)}\right]>0 .
\end{aligned}
$$

Therefore, the Hessian matrix is negative definite and $q^{*}$ and $b^{*}$ are the optimal solution. Just like Proposition 3, Proposition 4 shows that when the bank's variance risk limit is no lower than a certain level, the firm will not buy insurance. When the bank's risk limit is lower than the certain level, the firm should buy insurance and the optimal decision is what makes the bank's risk reach to its limit. The critical level is the risk taken by the bank when the firm orders the classical ordering quantity and does not buy insurance.

Corollary 1. For $\overline{v a r}=0$, the firm must buy the full insurance coverage, i.e. $b^{*}$ satisfies $b^{\star}=w q^{\star}+m\left(b^{\star}\right)$.

Proof: According the proof of Lemma 2, $T(b)$ is increasing in $b$, i.e. for $b^{0}$ which satisfies $b^{0}=\left(w q+m\left(b^{0}\right)\right)$ and $b^{1}$ which satisfies $b^{1}<\left(w q+m\left(b^{1}\right)\right)$, we have $b^{0}>b^{1}$. 
When $\overline{\operatorname{var}}=0$, we know $\operatorname{VarY}\left(q^{*}, b^{*}, r^{*}\left(q^{*}, b^{*}\right)\right)=0$ from Eq. (27). Define $b^{f}$ which satisfies $b^{f}=\left(w q^{*}+m\left(b^{f}\right)\right)\left(1+r^{*}\left(q^{*}, b^{f}\right)\right)$. From Eq. (7), we know $r^{*}\left(q^{*}, b^{f}\right)=0$, then we have $b^{f}=\left(w q^{*}+m\left(b^{f}\right)\right)$ and $\operatorname{VarY}\left(q^{*}, b^{f}, r^{*}\left(q^{*}, b^{f}\right)\right)=0$. From the proof of Lemma 3, because $\operatorname{Var} Y\left(q^{*}, b, r^{*}\left(q^{*}, b\right)\right)$ is strictly decreasing in $b$, we have $\operatorname{Var} Y\left(q^{*}, b, r^{*}\left(q^{*}, b\right)\right)>0$ for any $b$ which satisfies $b<\left(w q^{*}+m(b)\right)$. Hence, for $\overline{v a r}=0$, the firm must buy the full insurance coverage $b^{*}=b^{f}$.

From Corollary 1, if the bank does not want to bear any risk, the firm must buy the full insurance coverage. Otherwise, the firm could not borrow any capital from the bank. That is because the customer demand is random in $[0, \infty)$, and the bank's lending is risky at any loan level. In other words, unless the customer demand is certain in some range, the bank will not lend any money without full insurance coverage.

Corollary 2. For $0<\overline{\operatorname{var}}<\operatorname{VarY}\left(q^{N}, 0, r^{*}\left(q^{N}, 0\right)\right)$, the firm's optimal ordering quantity $q^{*}$ is always lower than the classical ordering quantity $q^{N}$, but higher than that without insurance $\bar{q}_{v}(0)$.

Proof: From Proposition 4, when $\overline{\operatorname{var}}<\operatorname{VarY}\left(q^{N}, 0, r^{*}\left(q^{N}, 0\right)\right)$, we have:

$$
q^{*}=F^{-1}\left[1-\frac{w\left(\left(w q^{*}+m\left(b^{*}\right)\right)\left(1+r^{*}\left(q^{*}, b^{*}\right)\right)-b^{*}\right)}{p\left(w q^{*}+m\left(b^{*}\right)-b^{*}\right)}\right] .
$$

Because $r^{*}\left(q^{*}, b^{*}\right) \geq 0$ and $F(\cdot)$ is increasing, we have $q^{*} \leq q^{N}$. Only when $\overline{v a r}=0$, $r^{*}\left(q^{*}, b^{*}\right)=0$ and $q^{*}=q^{N}$. When $0<\overline{\operatorname{var}}<\operatorname{Var} Y\left(q^{N}, 0, r^{*}\left(q^{N}, 0\right)\right)$, according to the $\operatorname{VarY}\left(q^{*}, b^{*}, r^{*}\left(q^{*}, b^{*}\right)\right)=\overline{\operatorname{var}}$ from Proposition 4 and $q^{*}<q^{N}$, we know $b^{*}>0$ since $\operatorname{Var} Y\left(q, b, r^{*}(q, b)\right)$ is decreasing in $b$. Because $\overline{\operatorname{var}}=\operatorname{Var} Y\left(\bar{q}_{v}(0), 0, r^{*}\left(\bar{q}_{v}(0), 0\right)\right)=$ $\operatorname{Var} Y\left(q^{*}, b^{*}, r^{*}\left(q^{*}, b^{*}\right)\right)<\operatorname{Var} Y\left(q^{*}, 0, r^{*}\left(q^{*}, 0\right)\right)$ and $\operatorname{Var} Y\left(q, b, r^{*}(q, b)\right)$ is increasing in $q$, we have $q^{\star}>\bar{q}_{v}(0)$.

From Corollary 2, if the risk degree that the bank can tolerate is low, the firm will not realize the classical ordering quantity and its profit will be subjected to loss during the operational decision. However, because of insurance, the profit reduction will be less. The firm's ordering quantity is higher than that without insurance.

Under the variance risk measurement, the firm's optimal ordering quantity and insurance coverage level for various risk limits are illustrated in Figs 2-5.

From the numerical analysis in the next section, we can see that the firm's marginal ordering limit first increases and then decreases with the insurance coverage level, i.e. the firm's ordering limit function is convex for the low coverage level and concave for the high coverage level. Therefore, the firm's ordering limit is a S-shaped curve as shown in Figs 3-5. Notice, when the bank sets the risk limit to zero, it essentially means that the firm will not get any loan unless it purchases full insurance coverage. And if the firm buys full insurance coverage, the bank has no risk thus there is no limit on the loan. In this case, the firm will order up to the classical ordering quantity. When the bank sets the risk limit between zero and $\operatorname{Var} Y\left(q^{N}, 0, r^{*}\left(q^{N}, 0\right)\right)$, the firm's optimal ordering quantity is greater than $\bar{q}_{v}(0)$, 


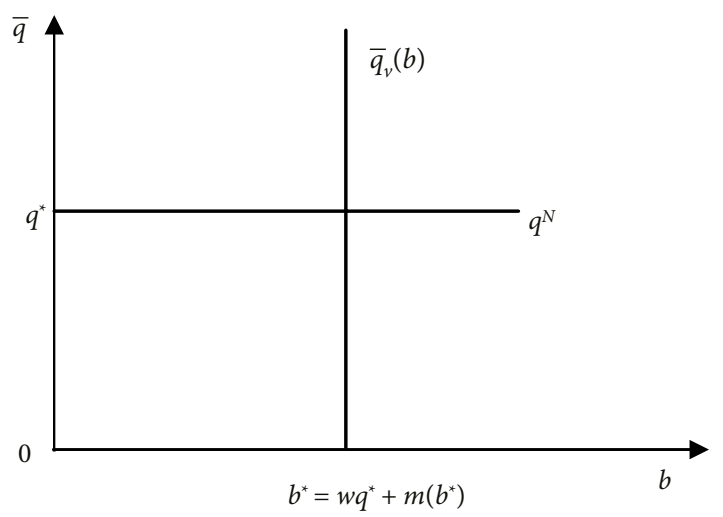

Fig. 2. The optimal ordering quantity and the optimal insurance coverage level when $\overline{v a r}=0$

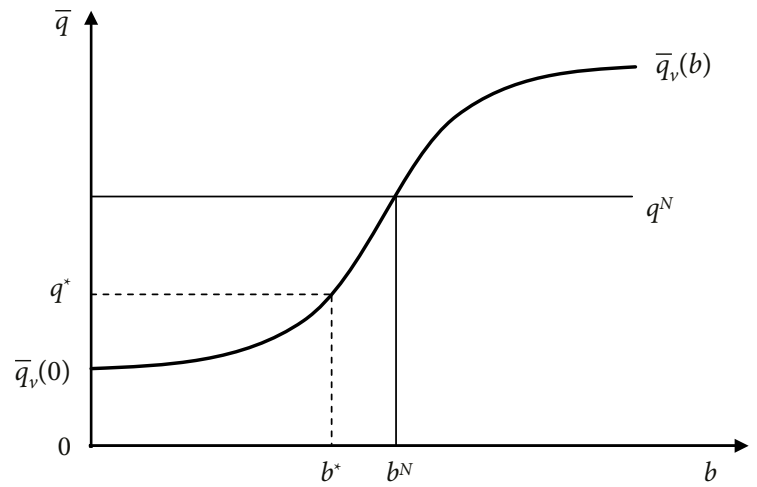

Fig. 3. The optimal ordering quantity and the optimal insurance coverage level when $0<\overline{\operatorname{var}}<\operatorname{Var} Y\left(q^{N}, 0, r^{*}\left(q^{N}, 0\right)\right)$

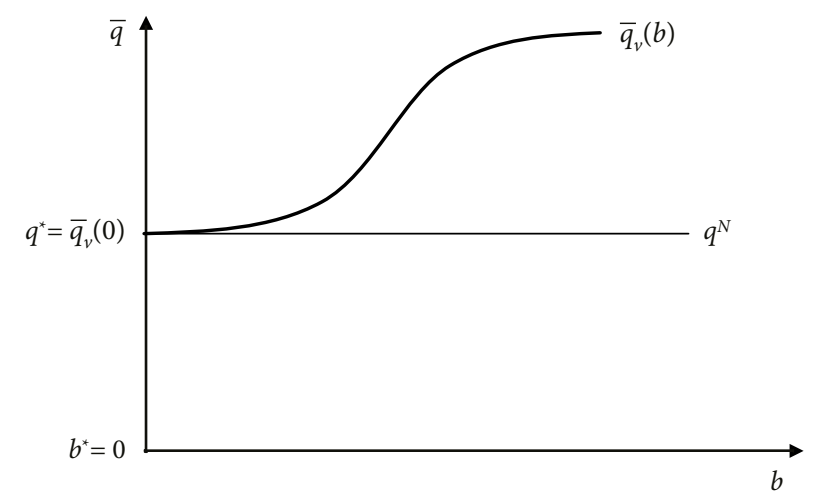

Fig. 4. The optimal ordering quantity and the optimal insurance coverage level when $\overline{\operatorname{var}}=\operatorname{VarY}\left(q^{N}, 0, r^{*}\left(q^{N}, 0\right)\right)$ 


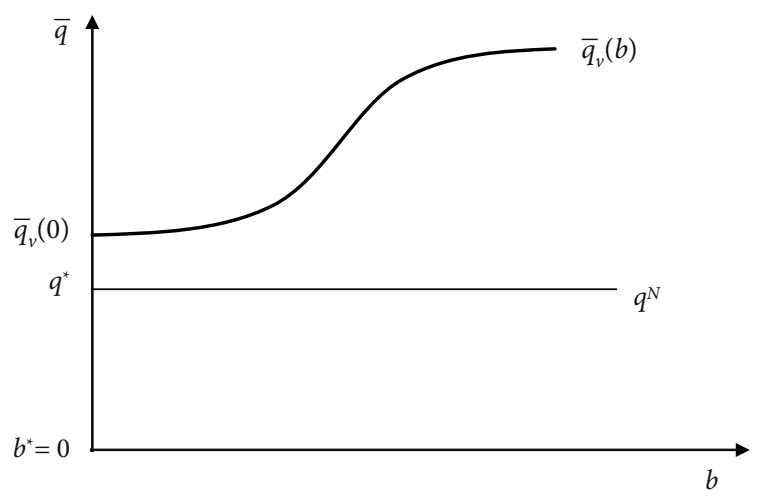

Fig. 5. The optimal ordering quantity and the optimal insurance coverage level when

$$
\overline{\operatorname{var}}>\operatorname{VarY}\left(q^{N}, 0, r^{*}\left(q^{N}, 0\right)\right)
$$

and less than $q^{N}$. The increased expected profit of the firm by buying an insurance policy is equal to $E \pi\left(q^{*}, b^{*}\right)-E \pi\left(\bar{q}_{v}(0), 0\right)$, and the increased expected return of the bank is $w\left(q^{*}-\bar{q}_{v}(0)\right)+m\left(b^{*}\right)$. In the other two situations, the firm's optimal ordering quantity is equal to the classical ordering quantity and insurance should not be purchased.

\section{Numerical examples}

To illustrate the analysis, we consider numerical examples with uniform demand distribution in $[0,100]$. Without insurance, the firm's expected profit is $E \pi^{N I}=(p-w) q^{N I}-p \frac{\left(q^{N I}\right)^{2}}{200}$. With an insurance contract, the firm's expected profit is $E \pi^{\star}=(p-w) q^{\star}-p \frac{q^{\star 2}}{200}-\frac{b^{\star 2}}{200 p}$. We define $\Delta \equiv \frac{E \pi^{*}-E \pi^{N I}}{E \pi^{N I}} \times 100 \%$ as the percentage increase in the profit of the firm with an insurance contract. Assume the wholesale price $w=1$. Under the downside risk measurement, we assume the bank's target NPL ratio $\alpha=0.1$. The firm's optimal ordering quantity and coverage level, expected profit and the percentage increase are shown in Table 1.

From Table 1, we can see that the firm will buy a credit insurance policy only when the bank's risk limit is low. That is because the bank is only concerned with downside risk. When the bank's risk limit is medium, a high coverage level costs too much and a low coverage level cannot reduce the downside risk, so the firm will not buy insurance and the optimal ordering quantity is small. From Proposition 3, it is easy to see that the firm will not buy insurance when the bank's risk limit is high. Given the selling price, if the firm buys an insurance policy, the optimal coverage level is independent of the bank's risk limit. It is also shown that given the selling price, $\Delta$ decreases with the bank's risk limit; while given the bank's risk limit, $\Delta$ increases with the selling price. Moreover, it is surprising that when the firm's optimal ordering quantity equals to $\bar{q}_{0}$, the bank's interest rate is only relevant to the risk limit, but 
irrelevant to the selling price. Note that $\bar{q}_{0}$ is relevant to the selling price. This means the bank's interest rate can also reflect the bank's risk attitude in a competitive financial market once the firm's ordering quantity reaches up to its affordable limit.

Under the bank's variance risk measurement, the firm's ordering limit and its marginal increase are shown in Table 2; the firm's optimal ordering quantity and coverage level, expected profit and the percentage increase are shown in Table 3.

Table 1. The firm's optimal decisions and profit under the bank's downside risk control

\begin{tabular}{ccccccccccc}
\hline$\beta$ & $p$ & $q^{*}$ & $b^{*}$ & $m\left(b^{*}\right)$ & $r^{*}\left(q^{*}, b^{*}\right)$ & $q^{N I}$ & $r^{N I}$ & $E \pi^{*}$ & $E \pi^{N I}$ & $\Delta$ \\
\hline 0.05 & 1.9 & $36.5599\left(q^{S}\right)$ & 35.9679 & 3.4044 & 0.0254 & 10.5556 & 0.0294 & 16.8015 & 8.4415 & $99.03 \%$ \\
0.1 & 1.9 & $36.5599\left(q^{S}\right)$ & 35.9679 & 3.4044 & 0.0254 & 21.1111 & 0.0627 & 16.8015 & 14.766 & $13.79 \%$ \\
0.15 & 1.9 & $31.6667\left(\bar{q}_{0}\right)$ & 0 & 0 & 0.101 & 31.6667 & 0.101 & 18.9736 & 18.9736 & $0 \%$ \\
0.2 & 1.9 & $42.2222\left(\bar{q}_{0}\right)$ & 0 & 0 & 0.1459 & 42.2222 & 0.1459 & 21.0642 & 21.0642 & $0 \%$ \\
0.25 & 1.9 & $47.3684\left(q^{N}\right)$ & 0 & 0 & 0.1709 & 47.3684 & 0.1709 & 21.3158 & 21.3158 & $0 \%$ \\
0.3 & 1.9 & $47.3684\left(q^{N}\right)$ & 0 & 0 & 0.1709 & 47.3684 & 0.1709 & 21.3158 & 21.3158 & $0 \%$ \\
0.35 & 1.9 & $47.3684\left(q^{N}\right)$ & 0 & 0 & 0.1709 & 47.3684 & 0.1709 & 21.3158 & 21.3158 & $0 \%$ \\
\hline 0.05 & 1.6 & $26.7878\left(q^{S}\right)$ & 26.012 & 2.1145 & 0.021 & 8.8889 & 0.0294 & 8.2175 & 4.7012 & $74.8 \%$ \\
0.1 & 1.6 & $26.7878\left(q^{S}\right)$ & 26.012 & 2.1145 & 0.021 & 17.7778 & 0.0627 & 8.2175 & 8.1383 & $0.97 \%$ \\
0.15 & 1.6 & $26.6667\left(\bar{q}_{0}\right)$ & 0 & 0 & 0.101 & 26.6667 & 0.101 & 10.3111 & 10.3111 & $0 \%$ \\
0.2 & 1.6 & $35.5556\left(\bar{q}_{0}\right)$ & 0 & 0 & 0.1459 & 35.5556 & 0.1459 & 11.2198 & 11.2198 & $0 \%$ \\
0.25 & 1.6 & $37.5\left(q^{N}\right)$ & 0 & 0 & 0.1568 & 37.5 & 0.1568 & 11.25 & 11.25 & $0 \%$ \\
0.3 & 1.6 & $37.5\left(q^{N}\right)$ & 0 & 0 & 0.1568 & 37.5 & 0.1568 & 11.25 & 11.25 & $0 \%$ \\
0.35 & 1.6 & $37.5\left(q^{N}\right)$ & 0 & 0 & 0.1568 & 37.5 & 0.1568 & 11.25 & 11.25 & $0 \%$ \\
\hline 0.05 & 1.3 & $14.8135\left(q^{S}\right)$ & 14.0117 & 0.7551 & 0.0129 & 7.2222 & 0.0294 & 2.2626 & 1.8276 & $23.8 \%$ \\
0.1 & 1.3 & $14.4444\left(\bar{q}_{0}\right)$ & 0 & 0 & 0.0627 & 14.4444 & 0.0627 & 2.9772 & 2.9772 & $0 \%$ \\
0.15 & 1.3 & $21.6667\left(\bar{q}_{0}\right)$ & 0 & 0 & 0.101 & 21.6667 & 0.101 & 3.4486 & 3.4486 & $0 \%$ \\
0.2 & 1.3 & $23.0769\left(q^{N}\right)$ & 0 & 0 & 0.1092 & 23.0769 & 0.1092 & 3.4615 & 3.4615 & $0 \%$ \\
0.25 & 1.3 & $23.0769\left(q^{N}\right)$ & 0 & 0 & 0.1092 & 23.0769 & 0.1092 & 3.4615 & 3.4615 & $0 \%$ \\
0.3 & 1.3 & $23.0769\left(q^{N}\right)$ & 0 & 0 & 0.1092 & 23.0769 & 0.1092 & 3.4615 & 3.4615 & $0 \%$ \\
0.35 & 1.3 & $23.0769\left(q^{N}\right)$ & 0 & 0 & 0.1092 & 23.0769 & 0.1092 & 3.4615 & 3.4615 & $0 \%$ \\
\hline & & & & & & & & & &
\end{tabular}

Table 2. The firm's ordering limit and its marginal increase under the bank's variance risk control $(p=1.6)$

\begin{tabular}{|c|c|c|c|c|c|c|c|c|c|c|c|}
\hline$\overline{v a r}$ & $b$ & 5 & 10 & 15 & 20 & 25 & 30 & 35 & 40 & 45 & 50 \\
\hline \multirow[b]{2}{*}{$\overline{\text { var }}=10$} & $\bar{q}_{v}(b)$ & 17.5116 & 19.9877 & 23.0884 & 26.4639 & 29.9432 & 33.4353 & 36.8872 & 40.2664 & 43.5515 & 46.728 \\
\hline & $\Delta \bar{q}_{v}(b)$ & 0 & 2.4761 & 3.1007 & 3.3755 & 3.4793 & 3.4921 & 3.4519 & 3.3792 & 3.2851 & 3.1765 \\
\hline \multirow[b]{2}{*}{$\overline{v a r}=30$} & $\bar{q}_{v}(b)$ & 24.1457 & 26.0451 & 28.5783 & 31.4565 & 34.5104 & 37.6377 & 40.7738 & 43.8762 & 46.9159 & 49.8722 \\
\hline & $\Delta \bar{q}_{v}(b)$ & 0 & 1.8994 & 2.5332 & 2.8782 & 3.0539 & 3.1273 & 3.1361 & 3.1024 & 3.0397 & 2.9563 \\
\hline \multirow[b]{2}{*}{$r=50$} & $\bar{q}_{v}(b)$ & 28.1352 & 29.7801 & 32.034 & 34.6473 & 37.4617 & 40.3753 & 43.3209 & 46.2526 & 49.1382 & 51.9544 \\
\hline & $\Delta \bar{q}_{v}(b)$ & 0 & 1.6449 & 2.2539 & 2.6133 & 2.8144 & 2.9136 & 2.9456 & 2.9317 & 2.8856 & 2.8162 \\
\hline
\end{tabular}


Table 3. The firm's optimal decisions and profit under the bank's variance risk control

\begin{tabular}{ccccccccccc}
\hline$\overline{v a r}$ & $p$ & $q^{*}$ & $b^{*}$ & $m\left(b^{*}\right)$ & $r^{*}\left(q^{*}, b^{*}\right)$ & $q^{N I}$ & $r^{N I}$ & $E \pi^{*}$ & $E \pi^{N I}$ & $\Delta$ \\
\hline 10 & 1.9 & 35.362 & 31.1244 & 2.5493 & 0.0408 & 17.4328 & 0.0506 & 17.397 & 12.8025 & $35.89 \%$ \\
30 & 1.9 & 36.2868 & 25.4619 & 1.7061 & 0.0694 & 24.8576 & 0.0757 & 18.4431 & 16.5018 & $11.76 \%$ \\
50 & 1.9 & 36.9864 & 21.0845 & 1.1699 & 0.0883 & 29.2632 & 0.0918 & 19.1219 & 18.2017 & $5.06 \%$ \\
70 & 1.9 & 37.6157 & 17.075 & 0.7673 & 0.1029 & 32.557 & 0.1045 & 19.6449 & 19.2317 & $2.15 \%$ \\
90 & 1.9 & 38.2325 & 13.0778 & 0.4501 & 0.1149 & 35.2394 & 0.1154 & 20.0728 & 19.91821 & $0.78 \%$ \\
110 & 1.9 & 38.8901 & 8.7406 & 0.201 & 0.1251 & 37.5262 & 0.125 & 20.4319 & 20.3955 & $0.18 \%$ \\
130 & 1.9 & 39.7185 & 3.1605 & 0.0263 & 0.1338 & 39.5325 & 0.1337 & 20.7336 & 20.7325 & $0.005 \%$ \\
\hline 10 & 1.6 & 26.293 & 19.7519 & 1.2192 & 0.0506 & 16.4115 & 0.0573 & 9.026 & 7.6922 & $17.34 \%$ \\
30 & 1.6 & 27.611 & 13.1927 & 0.5439 & 0.0841 & 23.3653 & 0.0861 & 9.9238 & 9.6517 & $2.82 \%$ \\
50 & 1.6 & 28.7743 & 7.2348 & 0.1636 & 0.1047 & 27.4791 & 0.1048 & 10.4773 & 10.4467 & $0.29 \%$ \\
70 & 1.6 & 37.5 & 0 & 0 & 0.1568 & 37.5 & 0.1568 & 11.25 & 11.25 & $0 \%$ \\
90 & 1.6 & 37.5 & 0 & 0 & 0.1568 & 37.5 & 0.1568 & 11.25 & 11.25 & $0 \%$ \\
110 & 1.6 & 37.5 & 0 & 0 & 0.1568 & 37.5 & 0.1568 & 11.25 & 11.25 & $0 \%$ \\
130 & 1.6 & 37.5 & 0 & 0 & 0.1568 & 37.5 & 0.1568 & 11.25 & 11.25 & $0 \%$ \\
\hline 10 & 1.3 & 16.1206 & 4.2949 & 0.0709 & 0.0664 & 15.2486 & 0.0667 & 3.0761 & 3.0632 & $0.42 \%$ \\
30 & 1.3 & 23.0769 & 0 & 0 & 0.1092 & 23.0769 & 0.1092 & 3.4615 & 3.4615 & $0 \%$ \\
50 & 1.3 & 23.0769 & 0 & 0 & 0.1092 & 23.0769 & 0.1092 & 3.4615 & 3.4615 & $0 \%$ \\
70 & 1.3 & 23.0769 & 0 & 0 & 0.1092 & 23.0769 & 0.1092 & 3.4615 & 3.4615 & $0 \%$ \\
90 & 1.3 & 23.0769 & 0 & 0 & 0.1092 & 23.0769 & 0.1092 & 3.4615 & 3.4615 & $0 \%$ \\
110 & 1.3 & 23.0769 & 0 & 0 & 0.1092 & 23.0769 & 0.1092 & 3.4615 & 3.4615 & $0 \%$ \\
130 & 1.3 & 23.0769 & 0 & 0 & 0.1092 & 23.0769 & 0.1092 & 3.4615 & 3.4615 & $0 \%$ \\
\hline
\end{tabular}

From Table 2, we can see that the firm's ordering limit $\bar{q}_{v}(b)$ increases and its marginal increase $\Delta \bar{q}_{v}(b)$ first increases and then decreases with the insurance coverage level. It means that when beginning to use insurance policy, the effect of insurance policy on enhancing the ordering limit is not very obvious; with the coverage level increases, the effect will gradually be more obvious; when the coverage level exceeds a certain extent, the effect will become unobvious again. From Table 3, we can see that given the selling price, the firm's optimal ordering quantity increases and optimal insurance coverage level decreases with the bank's risk limit under the insurance contract. Given the selling price, $\Delta$ decreases with the bank's risk limit. Given the bank's risk limit, $\Delta$ increases with the selling price. It means that the insurance contract has a more obvious effect on the profit increases when the selling price is high or the bank's risk limit is low. Furthermore, we find that if the selling price is high $(p=1.9)$ the firm will buy insurance to get a larger loan from the bank no matter what the bank's risk limit is. However, if the selling price is not high $(p=1.6)$ the firm will not buy insurance when the bank's risk limit is high $(\overline{v a r} \geq 70)$. If the selling price is low $(p=1.3)$ the firm will buy insurance only when the bank's risk limit is very low $(\overline{v a r}<30)$. We can also see that given the selling price, the bank's interest rate increases with the bank's risk limit no matter there is an insurance contract or not. Without insurance contract, the bank's interest rate is higher and the firm's ordering quantity is lower comparing to those with an insurance contract. It means that the insurance contract can reduce the bank's risk and enhance the firm's ordering quantity. 


\section{Conclusions}

Many start-up firms and fast-growing firms have capital constraints and need to borrow money from banks for their businesses. These firms have little fixed assets as collateral when they apply for loans. Banks often set loan limit for these firms to mitigate the risk associated with their default. In this paper, we study the optimal financial and ordering decisions of a capital-constrained firm. It is shown that the firm can make the bank's loan limit increase by buying a deductible insurance policy against the default risk. It is also shown that repayment demand level needed to avoid bankruptcy will not be affected by the insurance policy. We derive the firm's optimal ordering quantity and insurance coverage level under a downside risk measurement and a variance risk measurement separately. All our major results can be computed via explicit expressions. We find that when the risk limit that the bank can tolerate is smaller than a certain level, the firm's optimal ordering quantity will be less than the classical ordering quantity, but will be no less than the ordering quantity without insurance under both the downside risk measurement and the variance risk measurement. The firm should pay more attention to whether to buy insurance or not under the downside risk measurement and how much insurance coverage to buy under the variance risk measurement. Under the downside risk measurement, once the firm decides to buy insurance, the optimal coverage level is only relevant to the bank's target NPL ratio, but irrelevant to the bank's risk limit. One important assumption in our paper is that customer demand distribution is public information for both the insurance company and the bank. In practice, this assumption may be violated. It will be interesting to see how information asymmetry would affect the decisions of the firm and the bank. We leave it for future research.

\section{Acknowledgements}

The authors are very grateful for the kindly comments of the reviewers, which helped to significantly improve the quality of the paper. This work is supported by the Natural Science Foundation of China grant 71372107 and the Natural Science Foundation of China grant 71273159.

\section{References}

Anderson, M. H.; Prezas, A. P. 1998. The interaction of investment and financing decisions under moral hazard, International Review of Economics \& Finance 7(4): 379-392. http://dx.doi.org/10.1016/S1059-0560(98)90027-2

Babich, V.; Sobel, M. J. 2004. Pre-IPO operational and financial decisions, Management Science 50(7): 935-948. http://dx.doi.org/10.1287/mnsc.1040.0252

Brian, S. 2013. Just in case can credit insurance cover you?, Business Credit 115(8): 22-25.

Buzacott, J. A.; Zhang, R. Q. 2004. Inventory management with asset-based financing, Management Science 50(9): 1274-1292. http://dx.doi.org/10.1287/mnsc.1040.0278

Caillaud, B.; Dionne, G.; Jullien, B. 2000. Corporate insurance with optimal financial contracting, Economic Theory 16(1): 77-105. http://dx.doi.org/10.1007/s001990050328

Dermine, J.; Lajeri, F. 2001. Credit risk and the deposit insurance premium: a note, Journal of Economics and Business 53(5): 497-508. http://dx.doi.org/10.1016/S0148-6195(01)00045-5 
Dotan, A.; Ravid, S. A. 1987. On the interaction of real and financial decisions of the firm under uncertainty, The Journal of Finance 40(2): 501-507. http://dx.doi.org/10.1111/j.1540-6261.1985.tb04969.x

Guillen, G.; Badell, M.; Puigjaner, L. 2007. A holistic framework for short-term supply chain management integrating production and corporate financial planning, International Journal of Production Economics 106(1): 288-306. http://dx.doi.org/10.1016/j.ijpe.2006.06.008

Hu, Q.; Sobel, M. J. 2005. Capital structure and inventory management, Working paper. Case Western Reserve University.

Hu, Q.; Sobel, M. J. 2007. Echelon base-stock policies are financially sub-optimal, Operations Research Letters 35(5): 561-566. http://dx.doi.org/10.1016/j.orl.2006.11.001

Huang, S. H.; Sheoran, S. K.; Keskar, H. 2005. Computer-assisted supply chain configuration based on supply chain operations reference (SCOR) model, Computers \& Industrial Engineering 48(2): 377-394. http://dx.doi.org/10.1016/j.cie.2005.01.001

Jammernegg, W.; Kischka, P. 2012. Newsvendor problems with VaR and CVaR consideration, in T. M. Choi (Ed.). The handbook of newsvendor problems. New York: Springer Science Business Media. 395 p. http://dx.doi.org/10.1007/978-1-4614-3600-3_8

Kouvelis, P.; Zhao, W. 2011.The newsvendor problem and price-only contract when bankruptcy costs exist, Production and Operations Management 20(6): 921-936.

http://dx.doi.org/10.1111/j.1937-5956.2010.01211.x

Lai, G.; Debo, L. G.; Sycara, K. 2009. Sharing inventory risk in supply chain: the implication of financial constraint, Omega 37(4): 811-825. http://dx.doi.org/10.1016/j.omega.2008.06.003

Lai, V. S.; Soumar, I. 2010. Credit insurance and investment: a contingent claims analysis approach, International Review of Financial Analysis 19(2): 98-107. http://dx.doi.org/10.1016/j.irfa.2010.01.006

Lee, H. C.; Rhee, B. D. 2010. Coordination contracts in the presence of positive inventory financing costs, International Journal of Production Economics 124(2): 331-339. http://dx.doi.org/10.1016/j.ijpe.2009.11.028

Li, J.; Chen, J.; Wang, S. 2011. Risk management of supply and cash flows in supply chains. New York, Dordrecht, Heidelberg, London: Springer. 202 p. http://dx.doi.org/10.1007/978-1-4614-0511-5

Li, L.; Shubik, M.; Sobel, M. J. 2013. Control of dividends, capital subscriptions, and physical inventories, Management Science 59(5): 1107-1124. http://dx.doi.org/10.1287/mnsc.1120.1629

Li, Y.; Feng, G.; Tu, H. 2009. Loan limit analysis of down-risk-averse bank based on supply chain financial innovation, Journal of Systems Science and Mathematical Sciences 29(11): 1552-1558.

Myers, S. C. 1974. Interaction of corporate financing and investment decisions-implications for capital budgeting, Journal of Finance (29): 1-25. http://dx.doi.org/10.1111/j.1540-6261.1974.tb00021.x

Myers, S. C. 1977. Determinants of corporate borrowing, Journal of Financial Economics (5): 147-176. http://dx.doi.org/10.1016/0304-405X(77)90015-0

Pan, Y. 2008. Credit insurance financing mode is popular in Shenzhen, Nanfang Daily (December 5th).

Raghavan, N. R.; Mishra, V. K. 2011. Short-term financing in a cash-constrained supply chain, International Journal of Production Economics 134(2): 407-412. http://dx.doi.org/10.1016/j.ijpe.2009.11.014

Stiglitz, J. E. 1972. Some aspects of the pure theory of corporate finance: bankruptcies and take-overs, Bell Journal of Economics and Management Science (3): 458-482. http://dx.doi.org/10.2307/3003033

Tang, R. 2007. The market credit system construction using trade credit insurance, China Economic Times (October).

Tsai, C. Y. 2008. On supply chain cash flow risks, Decision Support Systems 44(4): 1031-1042. http://dx.doi.org/10.1016/j.dss.2007.12.006

Xu, X.; Birge, J. R. 2006. Equity valuation, production, and financial planning: a stochastic programming approach, Working Paper. The University of Chicago Graduate School of Business.

Yi, T. 2012. China export credit insurance company and bank of China jointly signed to Sunivo, China Finance Net (July 30th). 
Wenli WANG was born in Hubei province, China, in 1982. He obtained the Bachelor's degree in Wuhan University of Science and Technology in 2004, obtained the Master's degree in Harbin University of Commerce in 2007, and obtained Doctoral degree in Shanghai Jiao Tong University in 2013. Now he is a full-time Teacher in the School of Economics and Management, Taiyuan University of Science and Technology, China. His main research fields are supply chain management, risk management.

Jianwen LUO is a Professor in the School of Management, Shanghai Jiao Tong University, China. He has published research articles in Operations Research, Operations Research Letters, Journal of the Operational Research Society, International Journal of Production Economics, etc. He has also successfully proposed, directed and completed several projects supported by the National Natural Science Foundation of China. His research interests include logistics and supply chain management (especially in inventory systems), and stochastic programming and its applications in inventory control. 